\title{
Factors associated with mortality of patients with myxoedema coma: prospective study in 11 cases treated in a single institution
}

\author{
I Rodríguez, E Fluiters, L F Pérez-Méndez, R Luna, C Páramo and \\ R V García-Mayor \\ Endocrine Department, University Hospital of Vigo, Vigo, Spain \\ (Requests for offprints should be addressed to R V García-Mayor, PO Box 1691, 36201 Vigo, Spain; Email: ricardo.garcia.mayor@sergas.es or \\ rvgmayor@terra.es)
}

\begin{abstract}
This study was carried out to investigate the clinical and biochemical factors which might be of importance in predicting the outcome of patients with myxoedema coma. Eleven patients (ten female) aged $68 \cdot 1 \pm 19 \cdot 5$ years attended our institution over a period of 18 years.

Glasgow and APACHE II scores and serum free thyroxine and TSH were measured in all the patients on entry. Patients were selected at random to be treated with two different regimens of L-thyroxine.

Four patients died with the mortality rate being $36 \cdot 4 \%$. The patients in coma at entry had significantly higher mortality rates than those with minor degrees of consciousness ( $75 \%$ vs $14 \cdot 3 \%$ respectively, $P=0 \cdot 04$ ). The
\end{abstract}

surviving patients had significantly higher Glasgow scores than those who died $(11 \cdot 85 \pm 2 \cdot 3$ vs $5 \cdot 25 \pm 2 \cdot 2$ respectively, $P<0 \cdot 001)$. Comparison of the mean values of APACHE II scores between the surviving group and those who died was significantly different $(18 \cdot 0 \pm 2 \cdot 08$ vs $31 \cdot 5 \pm 2 \cdot 08$ respectively, $P<0 \cdot 0001)$.

The degree of consciousness, the Glasgow score and the severity of the illness measured by APACHE II score on entry were the main factors that determined the post-treatment outcome of patients with myxoedema coma.

Journal of Endocrinology (2004) 180, 347-350

\section{Introduction}

Myxoedema coma is a rarely occurring extreme expression of hypothyroidism. Recognition of this entity is hampered by its insidious onset and rarity. The incidence rate of this condition in our area is 0.22 per 1000000 per year (Galofré \& Garcia-Mayor 1997). In the past, the overall mortality rate for myxoedema was $60-70 \%$. Early recognition and advances in intensive supportive care have reduced the mortality rate to $20-25 \%$ (Jordan 1995).

The aim of the present study was to prospectively collect all cases of myxoedema coma which presented at our institution and investigate factors which might be of importance in predicting the outcome of these patients.

\section{Materials and Methods}

This prospective study includes all cases of myxoedema coma who presented at our institution from January 1985 to December 2002. Diagnosis of myxoedema coma was established by the following criteria: altered mental status, hypothermia $\left(\leq 35^{\circ} \mathrm{C}\right)$, a precipitating illness associated with low serum levels of thyroid hormones and increased levels of thyrotrophin (TSH), or depressed/normal levels of TSH associated with other pituitary damage or tumours. Eleven patients (ten female and one male) aged $68 \cdot 1 \pm 19 \cdot 5$ years, range $20-84$ years, were included in the present study. No patients had been previously diagnosed as having hypothyroidism. Eight had primary hypothyroidism (chronic autoimmune thyroiditis was diagnosed in cases 3, 5, 6, 7, 9 and 11, idiopathic hypothyroidism in case 1 and sublingual ectopic thyroid gland in case 8) and three had secondary hypothyroidism due to a non-functional pituitary macroadenoma (Table 1). Patients 1, 3, 4, 5 and 9 were diagnosed in winter. They were treated at the Intensive Care Unit of the University Hospital of Vigo.

Impaired consciousness was graded as obtundation, stupor or coma and by the Glasgow score (Wilson et al. 1998). The severity of the patients' illness was assessed by the APACHE II score, in which an increasing score is associated with an increasing risk of hospital death (Knaus et al. 1985).

The patients were treated with L-thyroxine (L-T4) following two regimens: six received an initial dose of $500 \mu \mathrm{g}$ i.v. ('high' dose) followed by a $100 \mu \mathrm{g}$ daily dose 
Table 1 Clinical and laboratory findings in eleven patients with myxoedema coma

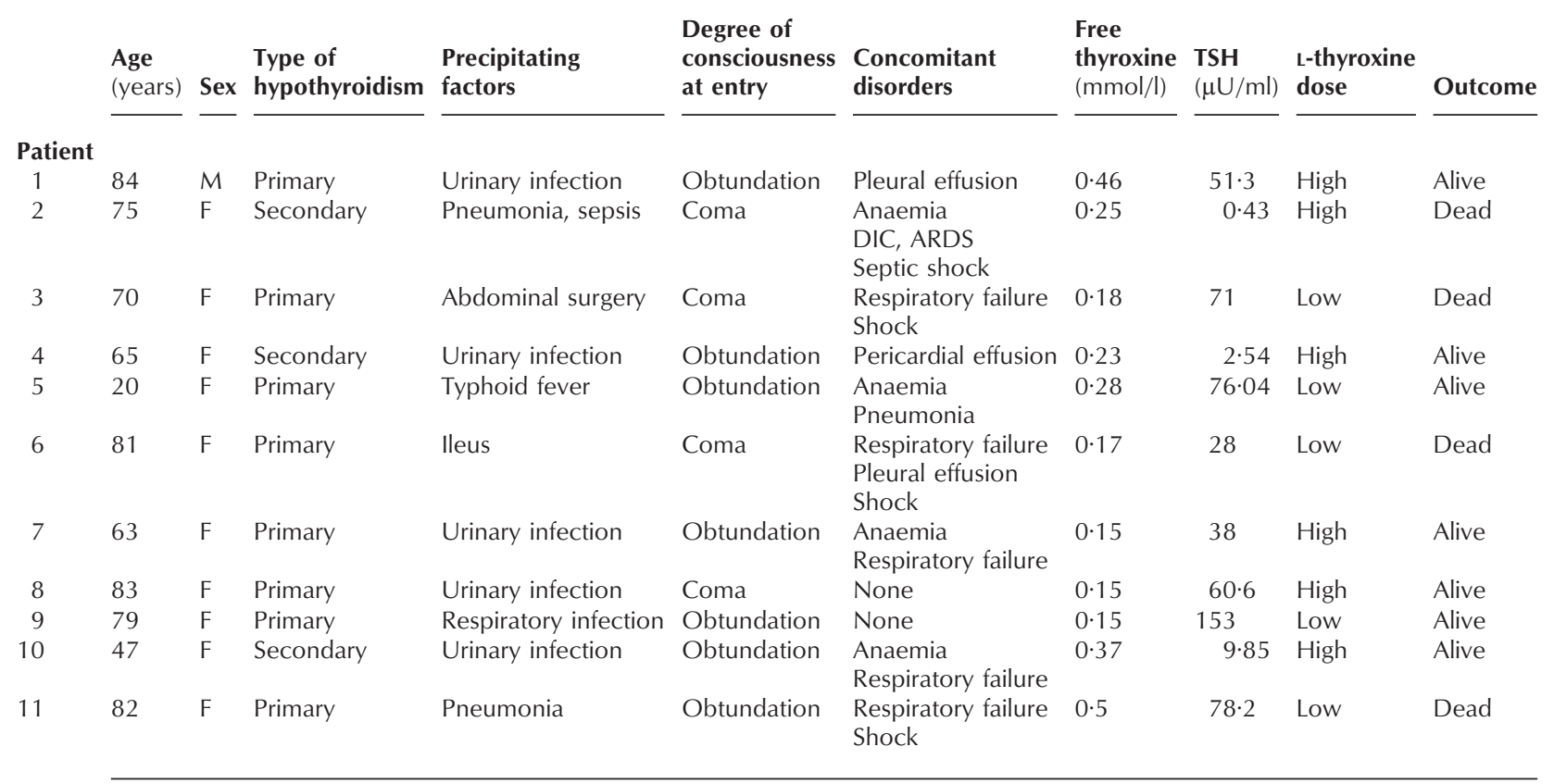

DIC, Disseminated Intravascular coagulation; ARDS, adult respiratory distress syndrome.

via the i.v. route until they regained their vital functions, the serum free thyroxine (T4) values were normalized and they were able to take oral medication; and the other five patients were treated similarly but without the initial high dose of L-T4 ('low' dose) (Table 1). The selection of patients who received either one or the other L-T4 regimen was at random with the aid of a table of random numbers. In addition, since starting the treatment all subjects had been given hydrocortisone acetate (200$400 \mathrm{mg}$ /day) until the possibility of coexisting adrenal insufficiency had been excluded. Before starting the treatment, serum samples for the determination of thyroid hormone and TSH levels were obtained and kept frozen $-40{ }^{\circ} \mathrm{C}$ until assayed in the same run.

The patients' relatives gave their informed consent before the participation of the patients in this protocol of treatment, which was approved by the Hospital Ethical Committee.

The mortality rate of myxoedema coma was determined. We also studied the mortality rates in the group of patients with primary hypothyroidism compared with the group with secondary hypothyroidism. To assess the role of improved equipment and the skill of the members of the Intensive Care Unit over the period of this study, we compared the mortality rates over two periods arbitrarily divided between 1985-1993 and 1994-2002.

We studied the clinical (age, body temperature, heart rate, degree of consciousness, Glasgow score and APACHE II score) and biochemical (free T4 and TSH) data at entry between the group of patients who survived and those who died. To assess the role of the dose of L-T4 used in the treatment, we compared the mortality rates and survival curves between the 'high' and the 'low' L-T4 dose groups.

Serum TSH (normal range 0.3-4.5 mU/1) and serum free $\mathrm{T} 4$ concentrations (normal range $0.7-1.9 \mathrm{mmol} / \mathrm{l}$ ) were measured by competitive chemiluminiscent enzyme immunoassay, using commercial kits (Diagnostic Products Corporation, Los Angeles, CA, USA).

\section{Statistical analysis}

Quantitative data are expressed as means \pm S.D. and their 95\% confidence intervals (CI). Differences between mean values were tested by Student's $t$-test with a previous verification of normality by the Kolmogorov-Smirnov test, whereas differences between percent values were assessed by the Chi-square test or exact Fisher's test when required. Treatment response was assayed for survival curves over 40 days using the Kaplan-Meier method whilst comparison of survival curves was assessed by the log-rank test.

\section{Results}

Four out of eleven patients died, with the mortality rate being $36 \cdot 4 \%$ (Table 1). The time until the patient died was 
Table 2 Variables used for APACHE II score calculations

\begin{tabular}{|c|c|c|c|c|c|c|c|c|c|c|c|c|c|}
\hline & $\begin{array}{l}\text { RT } \\
\left({ }^{\circ} \mathrm{C}\right)\end{array}$ & $\begin{array}{l}\text { Mean AP } \\
(\mathrm{mmHg})\end{array}$ & HR & $\mathbf{R} \mathbf{R}$ & $\mathrm{PaO}_{2}$ & $\begin{array}{l}\text { Arterial } \\
\mathrm{pH}\end{array}$ & $\begin{array}{l}\text { Serum } \\
\mathrm{Na}\end{array}$ & $\begin{array}{l}\text { Serum } \\
\mathrm{K}\end{array}$ & $\begin{array}{l}\text { Serum } \\
\mathrm{Cr}\end{array}$ & $\begin{array}{l}\text { Hct. } \\
(\%)\end{array}$ & $\begin{array}{l}\text { WBC } \\
\left(\times 10^{3}\right)\end{array}$ & $\begin{array}{l}\text { Glasgow } \\
\text { score }\end{array}$ & $\begin{array}{l}\text { APACHE II } \\
\text { score }\end{array}$ \\
\hline \multicolumn{14}{|c|}{ Patient } \\
\hline 1 & $34 \cdot 5$ & 110 & 39 & 24 & 68 & $7 \cdot 32$ & 133 & $4 \cdot 4$ & $1 \cdot 2$ & $40 \cdot 7$ & $3 \cdot 6$ & 13 & 18 \\
\hline 2 & $34 \cdot 4$ & 108 & 124 & 25 & 54 & $7 \cdot 30$ & 122 & $5 \cdot 5$ & $2 \cdot 4$ & $31 \cdot 0$ & $5 \cdot 4$ & 4 & 32 \\
\hline 3 & 33.9 & 115 & 38 & 15 & $204^{*}$ & $7 \cdot 31$ & 144 & $3 \cdot 9$ & $1 \cdot 4$ & $39 \cdot 3$ & $6 \cdot 2$ & 3 & 29 \\
\hline 4 & $34 \cdot 9$ & 74 & 104 & 14 & 76 & $7 \cdot 35$ & 124 & $2 \cdot 8$ & $1 \cdot 1$ & $44 \cdot 0$ & $4 \cdot 6$ & 8 & 17 \\
\hline 5 & $34 \cdot 2$ & 72 & 114 & 11 & 64 & $7 \cdot 34$ & 128 & 3.5 & $1 \cdot 1$ & $19 \cdot 0$ & $22 \cdot 0$ & 14 & 14 \\
\hline 6 & $34 \cdot 8$ & 68 & 38 & 10 & $505^{*}$ & $7 \cdot 30$ & 126 & 6.0 & $1 \cdot 4$ & $29 \cdot 0$ & 4.0 & 8 & 34 \\
\hline 7 & $35 \cdot 0$ & 88 & 124 & 20 & 68 & $7 \cdot 42$ & 110 & $4 \cdot 1$ & $1 \cdot 5$ & $29 \cdot 0$ & $16 \cdot 0$ & 13 & 18 \\
\hline 8 & $35 \cdot 0$ & 95 & 65 & 22 & 58 & $7 \cdot 48$ & 122 & $3 \cdot 5$ & $1 \cdot 4$ & $31 \cdot 4$ & $8 \cdot 0$ & 9 & 20 \\
\hline 9 & $34 \cdot 8$ & 128 & 52 & 18 & 58 & $7 \cdot 41$ & 120 & $3 \cdot 9$ & $1 \cdot 2$ & $35 \cdot 6$ & $9 \cdot 5$ & 13 & 19 \\
\hline 10 & $34 \cdot 9$ & 112 & 144 & 23 & 60 & $7 \cdot 31$ & 126 & $4 \cdot 6$ & 0.9 & $29 \cdot 0$ & $15 \cdot 4$ & 13 & 20 \\
\hline 11 & $33 \cdot 6$ & 80 & 38 & 10 & $360^{*}$ & $7 \cdot 30$ & 120 & $2 \cdot 7$ & $1 \cdot 3$ & $33 \cdot 0$ & $14 \cdot 0$ & 6 & 31 \\
\hline
\end{tabular}

$\mathrm{AP}$, arterial pressure; RT, rectal temperature; $\mathrm{HR}$, heart rate in beats/min; RR, respiratory rate in breaths/min; $\mathrm{Hct}$, haematocrit; WBC, white blood cells; FIO 2 fraction of inspired oxygen; *alveolar-arterial difference $\mathrm{O}_{2}$ when $\mathrm{FIO}_{2}>0 \cdot 05 ; \mathrm{Na}$ and $\mathrm{K}$ in $\mathrm{mEq} / \mathrm{l} ; \mathrm{Cr}$ in $\mathrm{mg} / \mathrm{dl}$.

4-15 days after the start of treatment. One patient died of septic shock (case 2) and three of circulatory failure (cases 3, 6 and 11). One out of three patients with secondary hypothyroidism and three out of eight patients with primary hypothyroidism died $(P=0.56$ for the difference in rates). On observing the mortality rates over the periods 1985-93 and 1994-2002, rates of three out of $\operatorname{six}(50 \%)$ and one out of five $(20 \%)$ for the former and latter groups were observed respectively $(P=0 \cdot 54)$.

The mean age of surviving patients was lower but not significantly different from the mean age of patients who died $(63 \cdot 0 \pm 23 \cdot 1$ and $77 \cdot 0 \pm 5 \cdot 6$ years respectively, $P=0 \cdot 27)$.

Neither the body temperature and the heart rates (Table 2) nor the mean values of free T4 $(0 \cdot 27 \pm 0 \cdot 15$ vs $0 \cdot 24 \pm 0 \cdot 10 \mathrm{mmol} / 1, P=0 \cdot 71)$ and TSH levels $(55.90 \pm$ $50 \cdot 27$ vs $44 \cdot 40 \pm 36 \cdot 75 \mathrm{mU} / 1)$ were different between the patients who survived and those who died.

With regard to the state of consciousness, three out of four patients who were in coma on admission died, whereas only one of seven patients with minor degrees of consciousness died, with the two mortality rates being significantly different $(P=0 \cdot 044)$. The patients in coma on entry had a mean survival of $16 \pm 7$ days (95\% CI, 2.14-29.86) while those with minor degrees of consciousness had a mean survival of $36 \cdot 4 \pm 3 \cdot 3$ days (95\% CI, 29.95-42.91), log-rank analyses revealed significant differences between both cumulative survival rates $(P=0 \cdot 019)$. Comparison of the mean values of Glasgow scores between the patients who survived and those who died was seen to be significantly different $(11 \cdot 85 \pm 3 \cdot 24$ vs $5 \cdot 25 \pm 2 \cdot 21$ respectively, $P<0 \cdot 001)$.

Comparison of the mean values of APACHE II scores between the patients who survived and those who died was significantly different $(18 \cdot 0 \pm 2.08$ vs $31.5 \pm 2 \cdot 08$ respectively, $P<0 \cdot 0001$ ) (Table 2 ). Furthermore, com- parison of the survival curves for patients who had $>20$ with those who had $\leq 20$ on the APACHE II score revealed significantly lower cumulative survival rates in the former group than in the latter $(19 \cdot 83 \pm 5.98$ (95\% CI, $8 \cdot 11-31 \cdot 56)$ vs 40 days respectively, log-rank $P=0 \cdot 031)$.

Comparison of the mortality rates between the 'high' L-T4 dose and the 'low' L-T4 dose groups revealed that the former group had a lower mortality rate than the latter (16.7\% vs $60 \%$ respectively) but the difference did not reach statistical significance. Likewise, comparison of the cumulative survival rates between both groups showed that the former group had a survival rate of $35 \cdot 33 \pm 4 \cdot 26$ days (95\% CI, 26.98-43.68) and the latter group of $21 \cdot 4 \pm 6 \cdot 9(95 \% \mathrm{CI}, 7 \cdot 73-35 \cdot 06)(P=0 \cdot 13)$.

\section{Discussion}

The main flaw of the present investigation was the small sample of patients. However, it had the advantage of being a prospective study, having a homogeneous sample of patients treated in a single institution with a previously established protocol, which made the comparison between the subgroups easier.

The mortality rate of myxoedema coma in the present investigation was similar to most recent reports (Jordan 1995, Yamamoto et al. 1999).

Ageing has been associated with a fatal outcome of myxoedema coma (Hylander \& Rosenquist 1985, Jordan 1995); in line with this, the mean age of our surviving patients was lower than those who died, although this difference was not statistically significant.

The clinical features of thyroid insufficiency resulting from TSH deficiency are similar to those of primary hypothyroidism. They are, however, generally less 
pronounced. In this study the mortality rates for both kinds of hypothyroidism were similar.

The term myxoedema coma is used more broadly and includes patients who, although not yet in coma, demonstrate a clear deterioration of their mental status, exhibiting lethargy, psychotic symptomatology or even more subtle signs, such as confusion and disorientation (Tsitouras 1995, Reinhardt \& Mann 1997). In the present study, the analyses of mortality rates and survival curves between the surviving and non-surviving groups of patients clearly demonstrated that the risks of mortality in these patients were related to the degrees of consciousness and to the Glasgow scores. Furthermore, the outcomes of these patients were also related to the severity of the patients' illness on entry determined by the APACHE II score. In this sense, the patients with an APACHE II score of more than 20 had high mortality risks, in agreement with previous data for other clinical conditions (Olalla Gallo et al. 1999). However, these data are in conflict with data reported by Yamamoto et al. (1999) who did not find any differences by simple inspection of APACHE II score between two patients who died and their other six surviving patients. However, these authors did not indicate at what moment during the patient's treatment the score was determined and statistical analysis was not performed.

Intravenous bolus administration of 300-500 $\mu \mathrm{g} \mathrm{L}-\mathrm{T} 4$ at the beginning of treatment followed by $50-100 \mu \mathrm{g}$ daily is considered to be safe and has remained a standard thyroid hormone replacement for the past three decades (Holvey et al. 1964, Ridgway et al. 1972). However, some investigators have reported a better treatment response using a low dose of L-T4 than with classical recommendations (Khaleeli 1978, Pereira et al. 1982, Yamamoto et al. 1999). Our results suggested that the patients treated with a high initial dose of L-T4 had a tendency towards better prognoses than those treated without that dose of levothyroxine which is in line with the aforementioned reports.

In conclusion, the results of the present investigation indicate that the degree of consciousness, the Glasgow score and the severity of the illness measured by the APACHE II score on entry are the main factors that determine the post-treatment outcome of patients with myxoedema coma. Furthermore, it also suggests that those patients who received an initial i.v. high dose of L-T4 had better prognoses than those who received less vigorous regimens.

\section{Acknowledgements}

The authors thank Mr Anthony J Rostron for his assistance with the manuscript.

\section{Funding}

This work was supported by a grant from the Conselleria de Presidencia of the Galician Government.

\section{References}

Galofré JC \& García-Mayor RV 1997 Densidad de incidencia del coma mixedematoso. Endocrinología 44 103-104.

Holvey DN, Goodner CJ, Nicoloff JT \& Dowling J 1964 Treatment of myxoedema coma with intravenous thyroxine. Archives of Internal Medicine 113 139-146.

Hylander B \& Rosenquist U 1985 Treatment of myxoedema coma factors associated with fatal outcome. Acta Endocrinologica 108 65-71.

Jordan RM 1995 Myxedema coma. Pathophysiology, therapy, and factors affecting prognosis. Medical Clinics of North America 79 185-194.

Khaleeli AA 1978 Myxxoedema coma. A report of five successfully treated cases. Postgraduate Medical Journal 54 825-829.

Knaus WA, Draper EA, Wagner DP \& Zimmerman JE 1985 APACHE II: a severity of disease classification system. Critical Care Medicine 13 818-829.

Olalla Gallo MA, Hernansanz de la Calle S, Hernández Bezos S, Fadrique Toledano R, Majo Fierro T \& Gandia Martí nez F 1999 Evaluación del APACHE II como sistema de estratificación de gravedad en unidades de observación de urgencias. Emergencias $\mathbf{1 1}$ 26-33.

Pereira VG, Haron ES, Lima-Neto G \& Medeiros-Neto GA 1982 Management of myxedema coma: report of three successfully treated cases with nasogastric or intravenous administration of triiodothyronine. Journal of Endocrinological Investigation 5 331-334.

Reinhardt W \& Mann K 1997 Hä ufigkeit, klinisches Bild und Behandlung des hypothyreoten Komas. Ergebnis einer Umfrage. Medizinische Klinik 92 521-524.

Ridgway EC, McCammon JA, Benotti J \& Maloof F 1972 Acute metabolic response in myxedema to large doses of intravenous L-thyroxine. Annals of Internal Medicine 77 549-555.

Tsitouras PD 1995 Myxedema coma. Clinical Geriatric Medicine 11 251-258.

Wilson JT, Pettigrew LE \& Teasdale GM 1998 Structured interviews for the Glasgow Outcome scale and the extended Glasgow Outcome scale: guidelines for their use. Journal of Neurotrauma $\mathbf{8}$ 573-585.

Yamamoto T, Kukurama J \& Fujiyoshi A 1999 Factors associated with mortality of myxedema coma: report of eight cases and literature survey. Thyroid 9 1167-1172.

Received in final form 22 October 2003

Accepted 6 November 2003 